\title{
S House n. 3
}

\author{
Vo Trong Nghia
}

ABSTRACT - The third prototype house for low-income classes designed in response to housing shortages in countries struck by natural disasters was built in Ho Chi Minh City. Thanks to passive design methods, natural lighting, a galvanized steel structure that weights only $1,200 \mathrm{~kg}$ set on a reinforced concrete foundation, the model combines quality control, cost management, easy transportation, DIY modular components and fast on-site construction. Now suitable for mass production, the S HOUSE project is designed to be flexible and adaptable to expansion or new uses as the next prototypes will showcase.

Keywords: Low-cost housing, disaster relief, prefabrication, durability, housing prototype

The serial project, called "S HOUSE," has begun to propose a prototype house for low-income classes in the Mekong Delta area. After building two successful case-study houses, a steel structure model in 2012 and a precast concrete structure model in April 2014, a new prototype, S HOUSE 3, was constructed in Ho Chi Minh City.

The aim of this serial project is to provide stable but lightweight, permanent but affordable homes for low-income earners in a harsh tropical climate. Although there are many local challenges such as weak ground condition, frequent typhoon and potential earthquake, the structure is stable enough to withstand natural disasters. Passive design methods 
are applied throughout the series, including but not limited to, natural lighting and ventilation.

Combining the advantages of the first and second prototype, S HOUSE 3 realizes a higher of durability, flexibility and easier construction while maintaining the affordability and lightweight of the series. The main structure is made from lightweight steel. Slender steel lattice walls secure, support, and rigidify the whole frames. Thus the number of beams is minimized, reducing steel quantity greatly compared to previous prototypes - this structure only $1.200 \mathrm{~kg}(2,645 \mathrm{lb})$. Pedestal, incorporated with foundation, is made of reinforced concrete. Thanks to this, the galvanized steel structure is isolated from the ground, ensuring its durability even in a climate of high temperature and high humidity.

As was in the previous prototypes, the basic strategy of construction is a combination of modular structural components and DIY (do-it-yourself) finishes. Prefabrication helps to control quality, cost management, and future mass production. Galvanized steel frame and precast concrete foundation guarantee predetermined stability and accuracy. The lightweight structure allows smaller foundation and transportability by small boats, since waterways are still the dominant means of transport in certain areas in Vietnam. By pouring additional concrete, this compact foundation can be extended on site if necessary. Light frames with simple bolted connection also encourage dwellers and neighbors to participate in construction. All components are designed to be lighter than $60 \mathrm{~kg}(132 \mathrm{lb})$, to allow easier transportation and construction - in fact, it takes only three hours to assemble the whole structure and roof. Finishing materials can all be assembled and replaced easily by dwellers and neighbors. For the prototype, lightweight cement board is chosen for cladding.

Starting from the Mekong Delta, the S HOUSE project is aiming to be disseminated to the entire Vietnam, South East Asia, India and African countries, and to the rest of the world where low-income people are suffering from poorly built environment. Lightweight components of the S HOUSE are designed to be transportable by means of shipping containers. The latest prototype in progress, S HOUSE 4, will span a much larger space. Therefore, it is more flexible in use compared to the previous prototypes. Not being limited to housing, it can accommodate various functions such as retail, school and clinic, which are increasingly demanded in developing countries. 


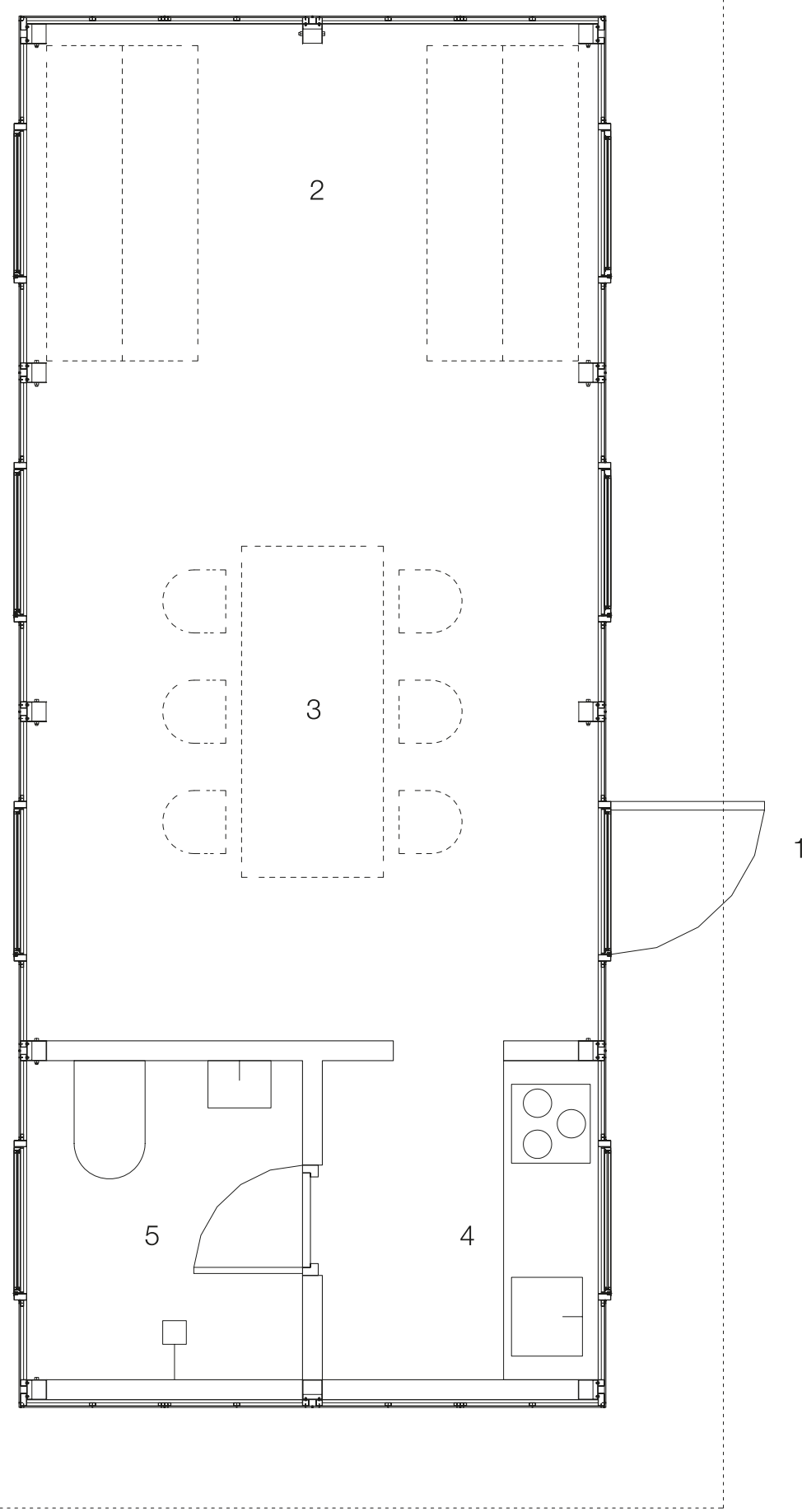

Figure 1. Floor plan.

1. Entrace

2. Bedroom

3. Living \& Dining room

4. Kitchen

5. Bathroom 

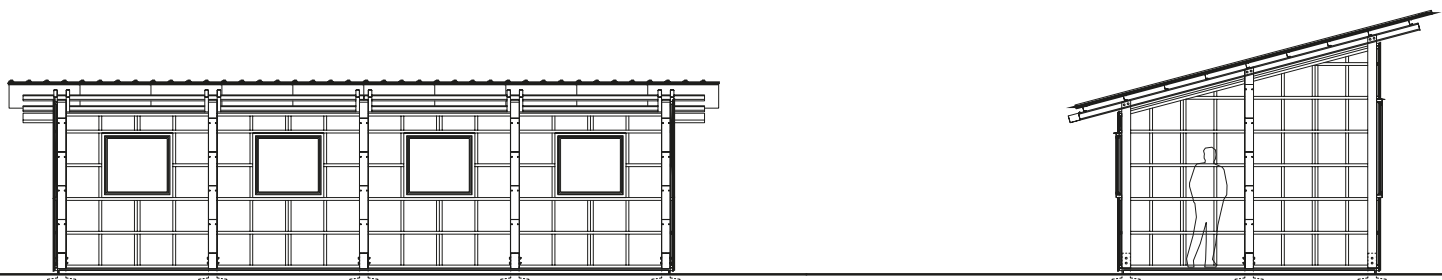

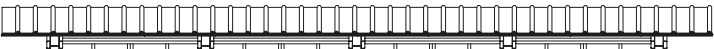
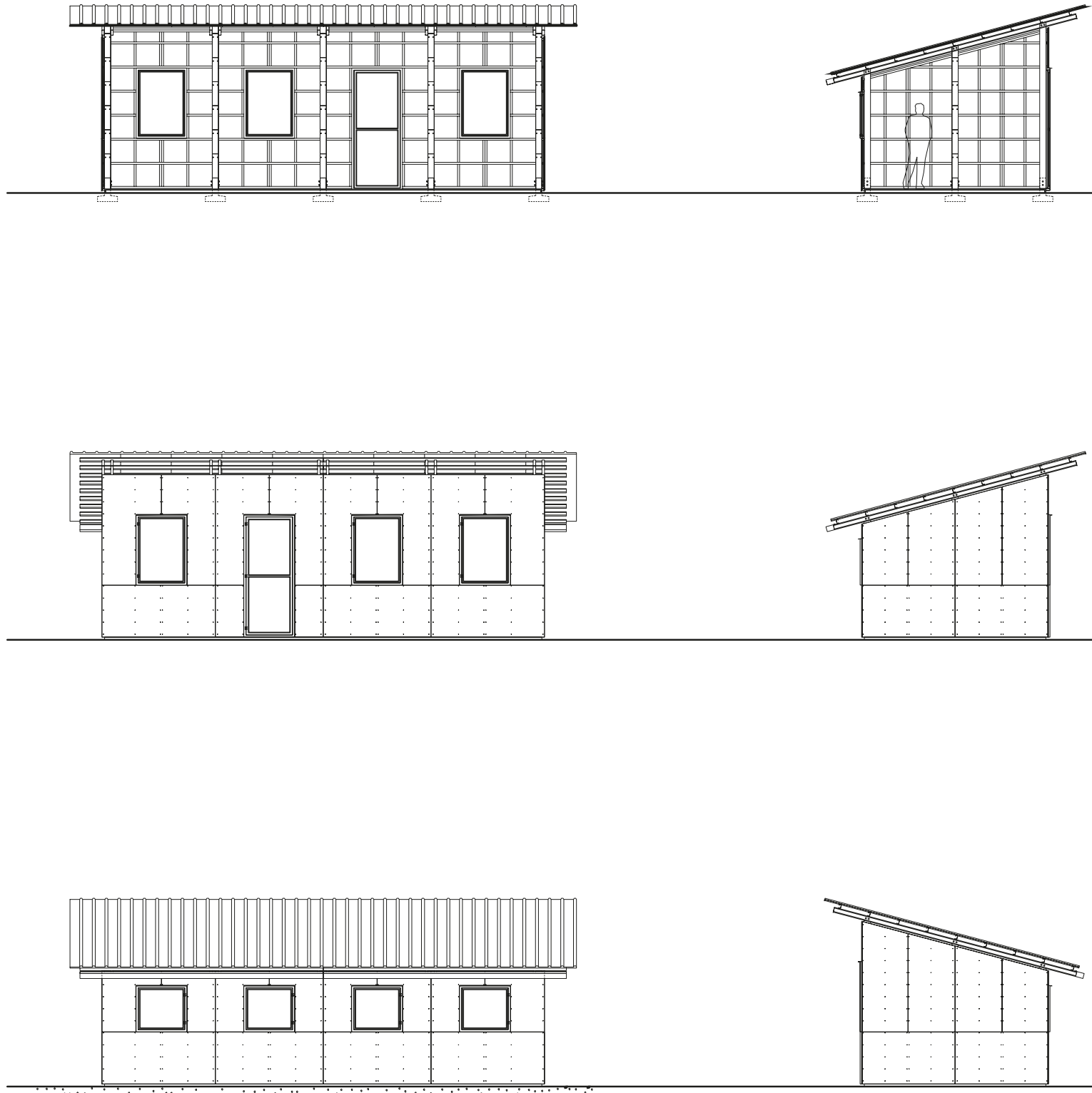

Figure 2. Sections and elevations. 


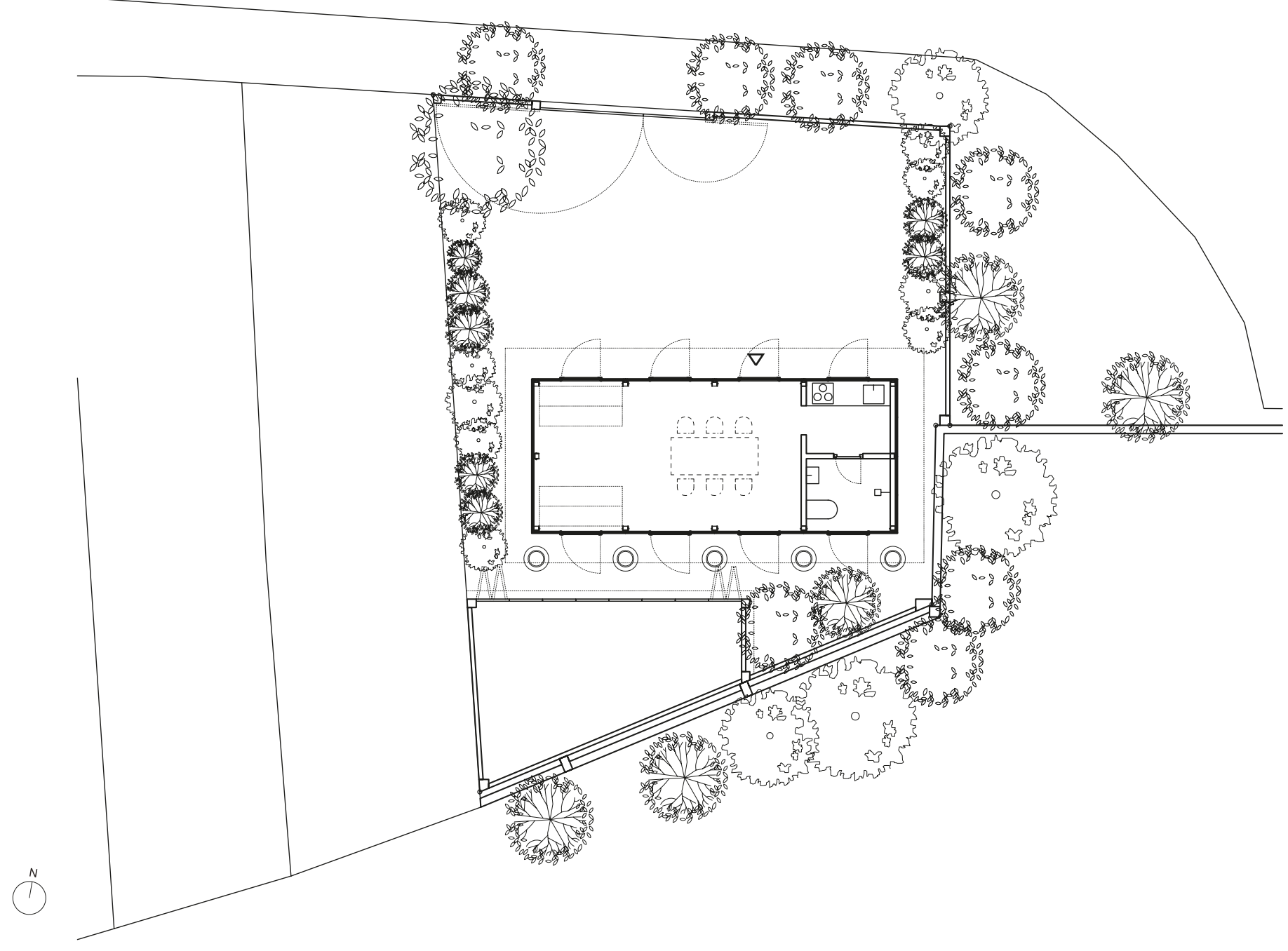

Figure 3. Site plan on a typical urban plot in Vietnam. 


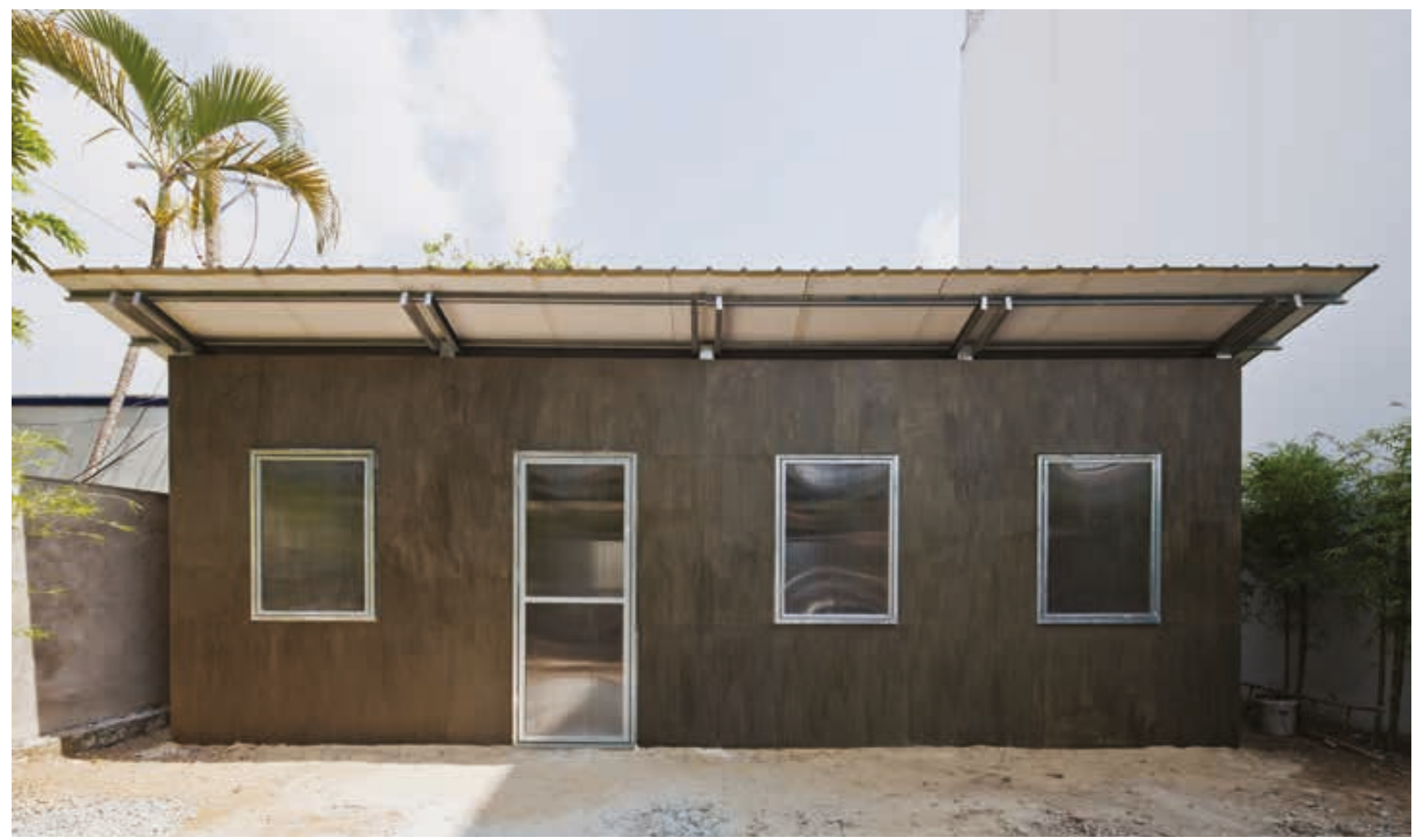

Figure 4. The S House 3, by Vo Trong Nghia Architects. (C Hiroyuki Oki.

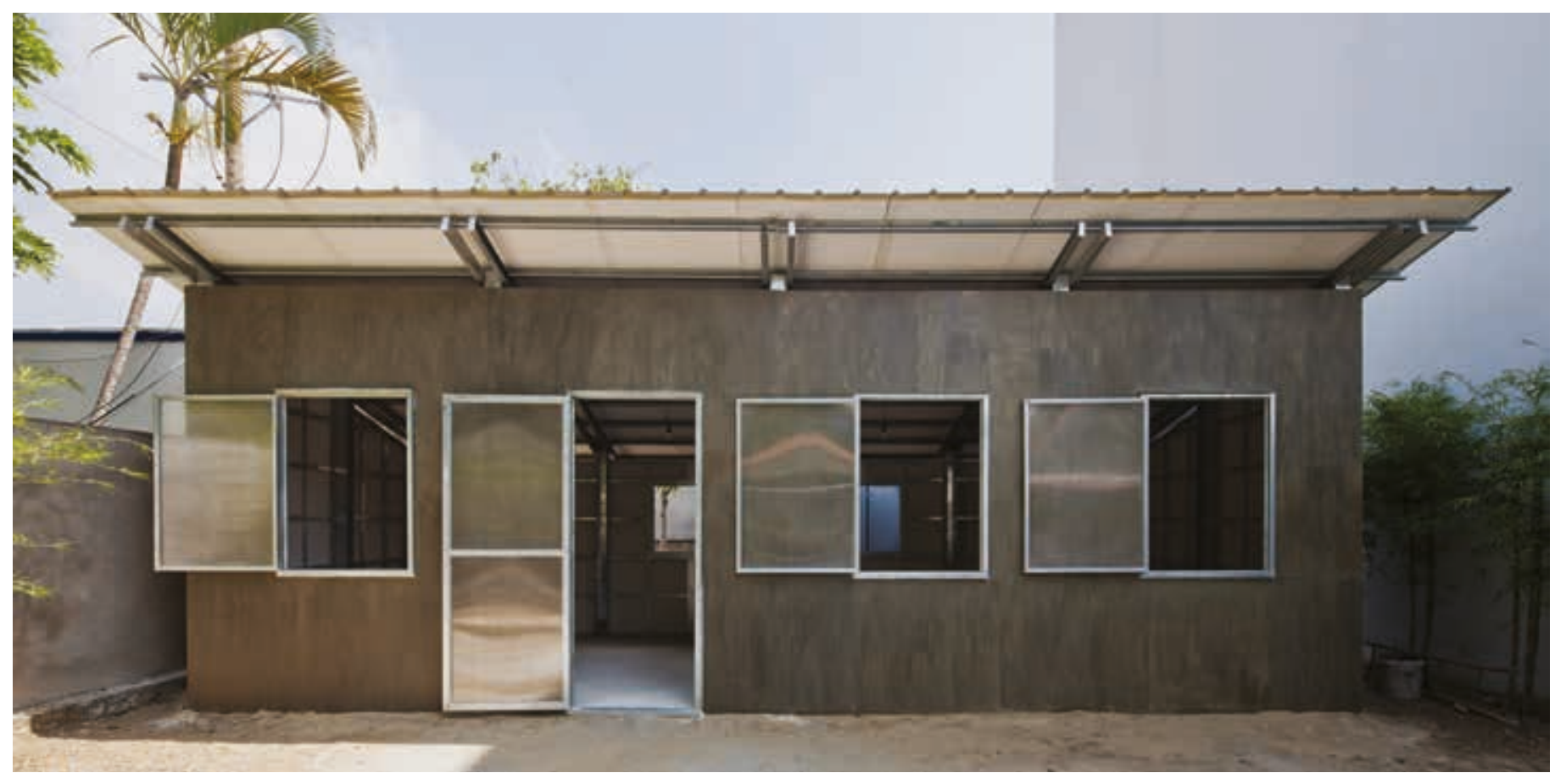

Figure 5. Like its predecessor, the $S$ House 3 features a small gap between its roof and walls to encourage ventilation, and several operable windows. (c) Hiroyuki Oki. 


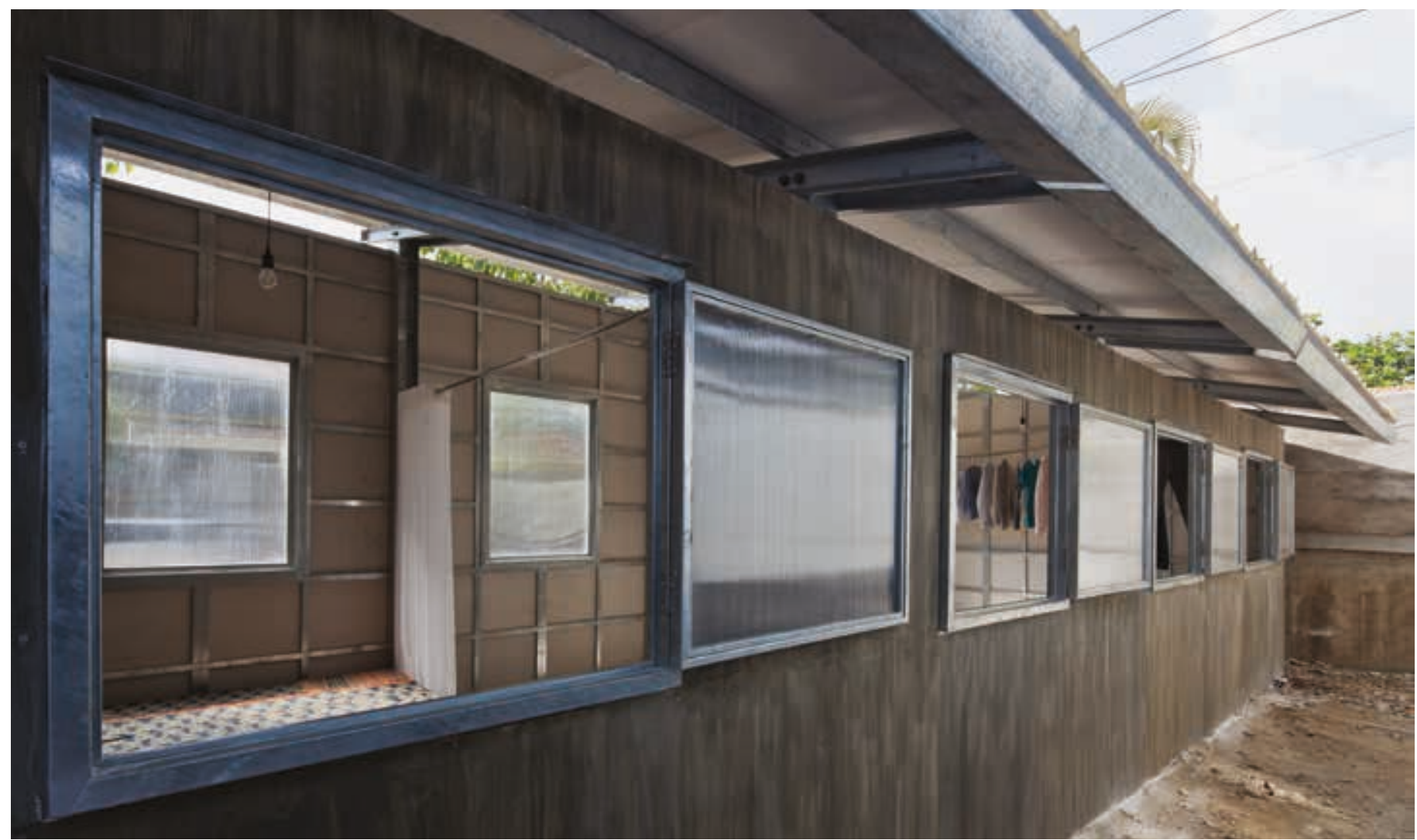

Figure 6 . Though the house weighs $1,200 \mathrm{~kg}(2,645 \mathrm{lb})$, individual components are designed to be lighter than $60 \mathrm{~kg}$ (132 lb), to allow easier transportation. (C) Hiroyuki Oki.

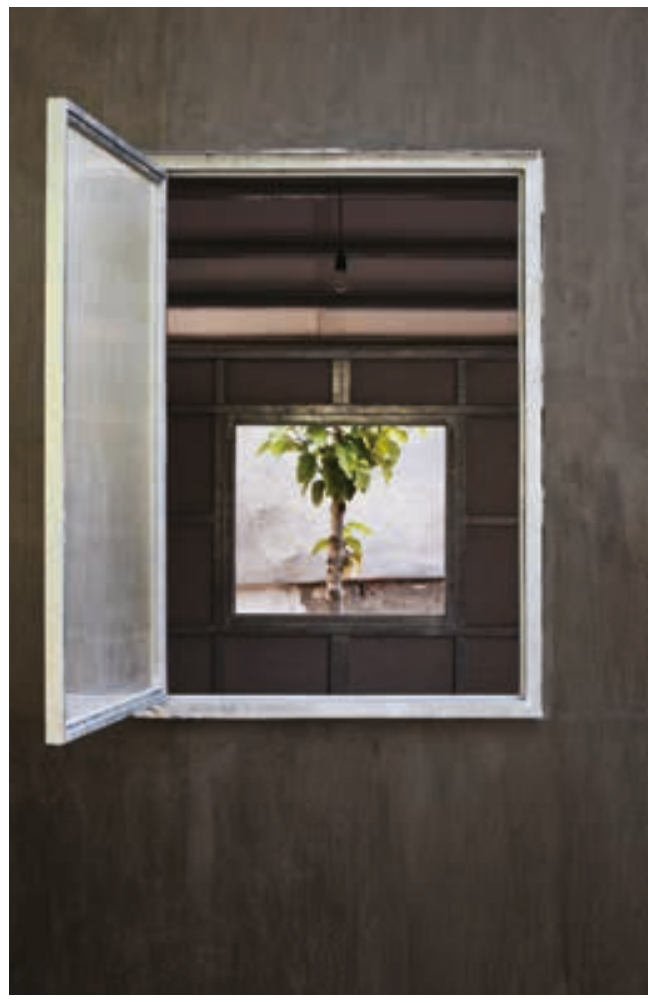

Figure 7. Whereas the previous S House was built from a pre-cast concrete frame bolted together with steel fixings, this newest version is made mostly from lightweight steel. (c) Hiroyuki Oki. 


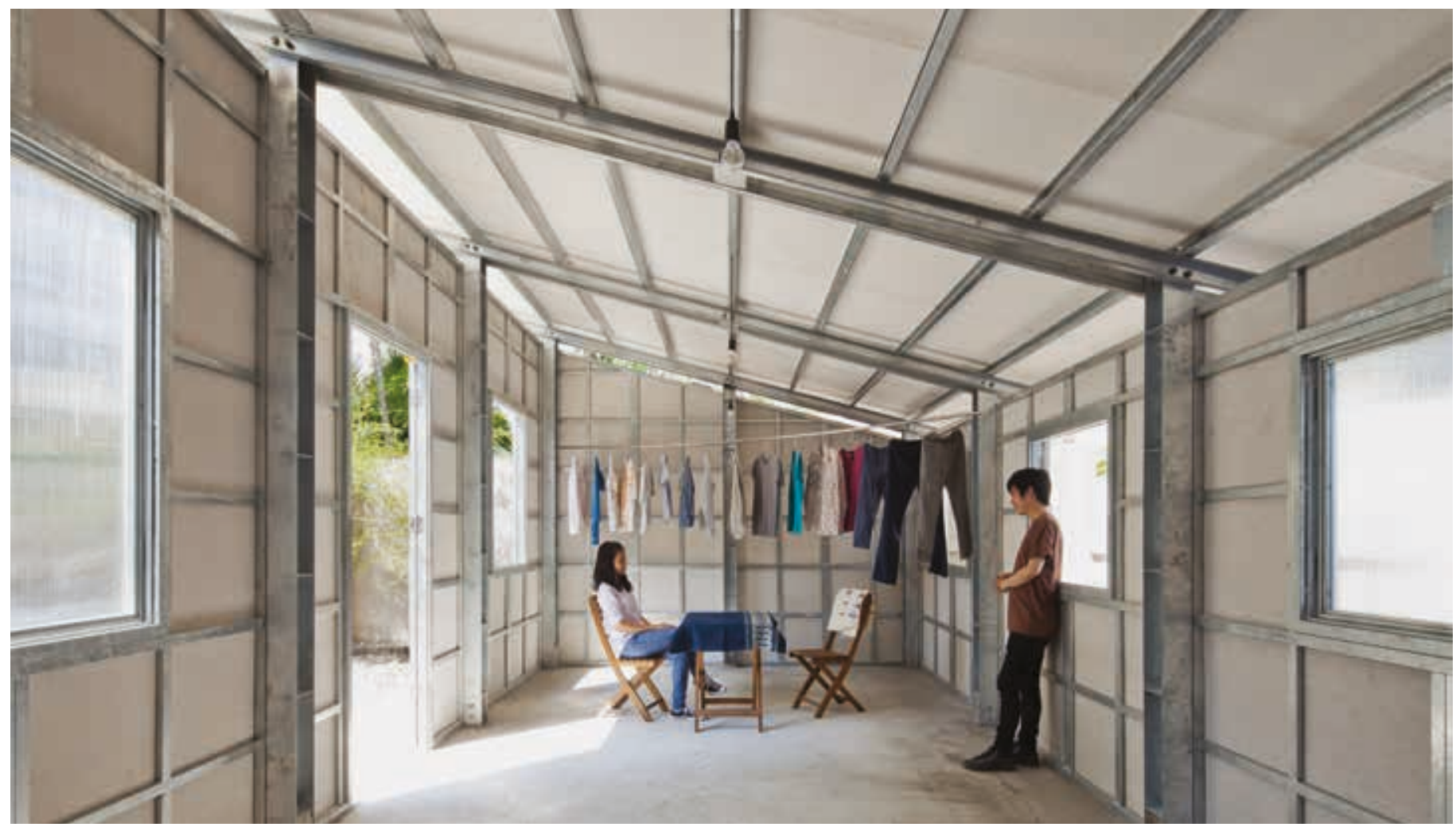

Figure 8. the S House 3 measures $31.6 \mathrm{sq} \mathrm{m} \mathrm{(340} \mathrm{sq} \mathrm{ft)} \mathrm{and} \mathrm{has} \mathrm{just} \mathrm{one} \mathrm{large} \mathrm{interior}$ space inside. (C) Hiroyuki Oki.

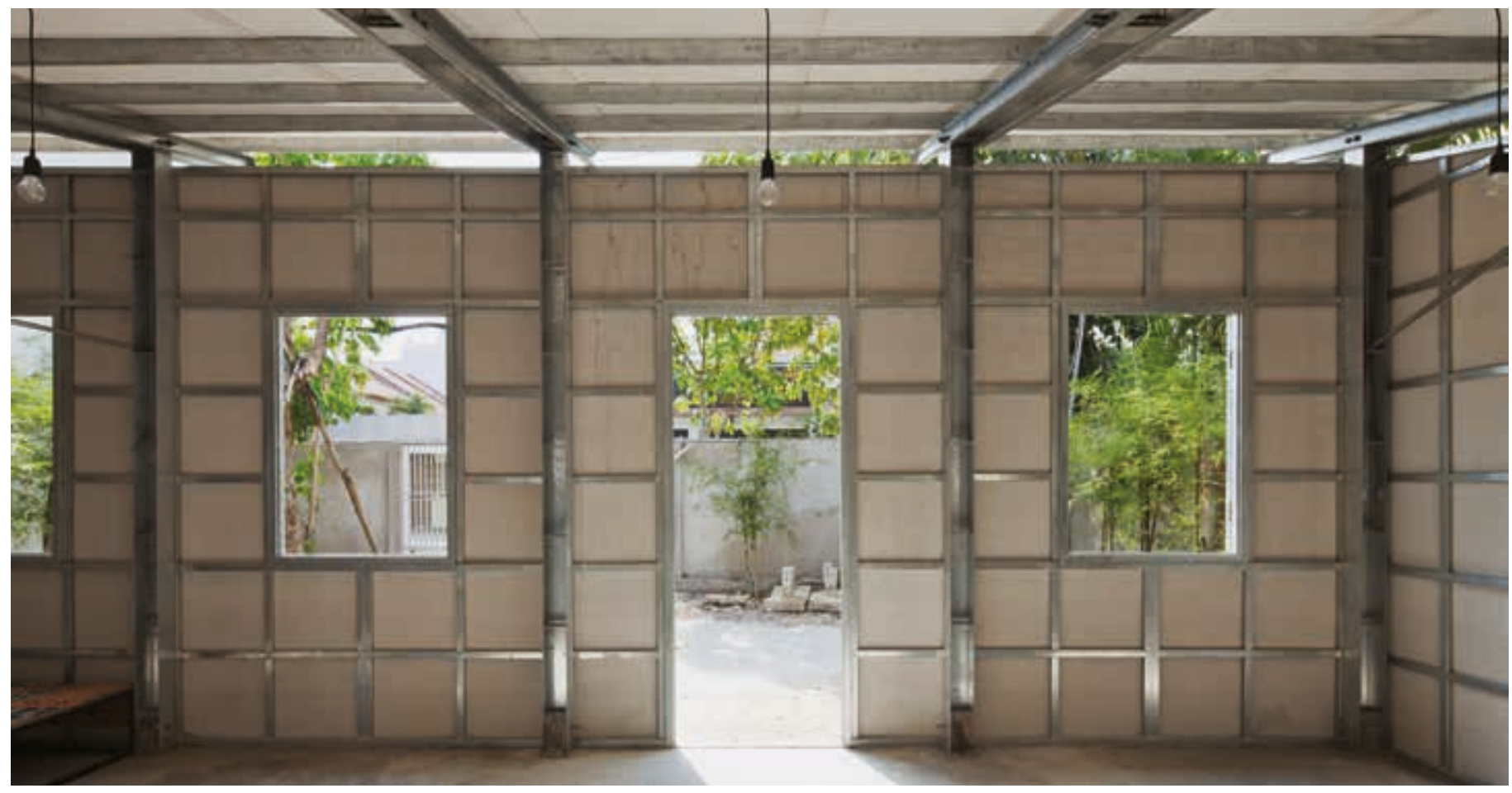

Figure 9. Vo Trong Nghia's third prototype for the $S$ House has both a steel frame with a concrete foundation and steel lattice walls. (c) Hiroyuki Oki. 


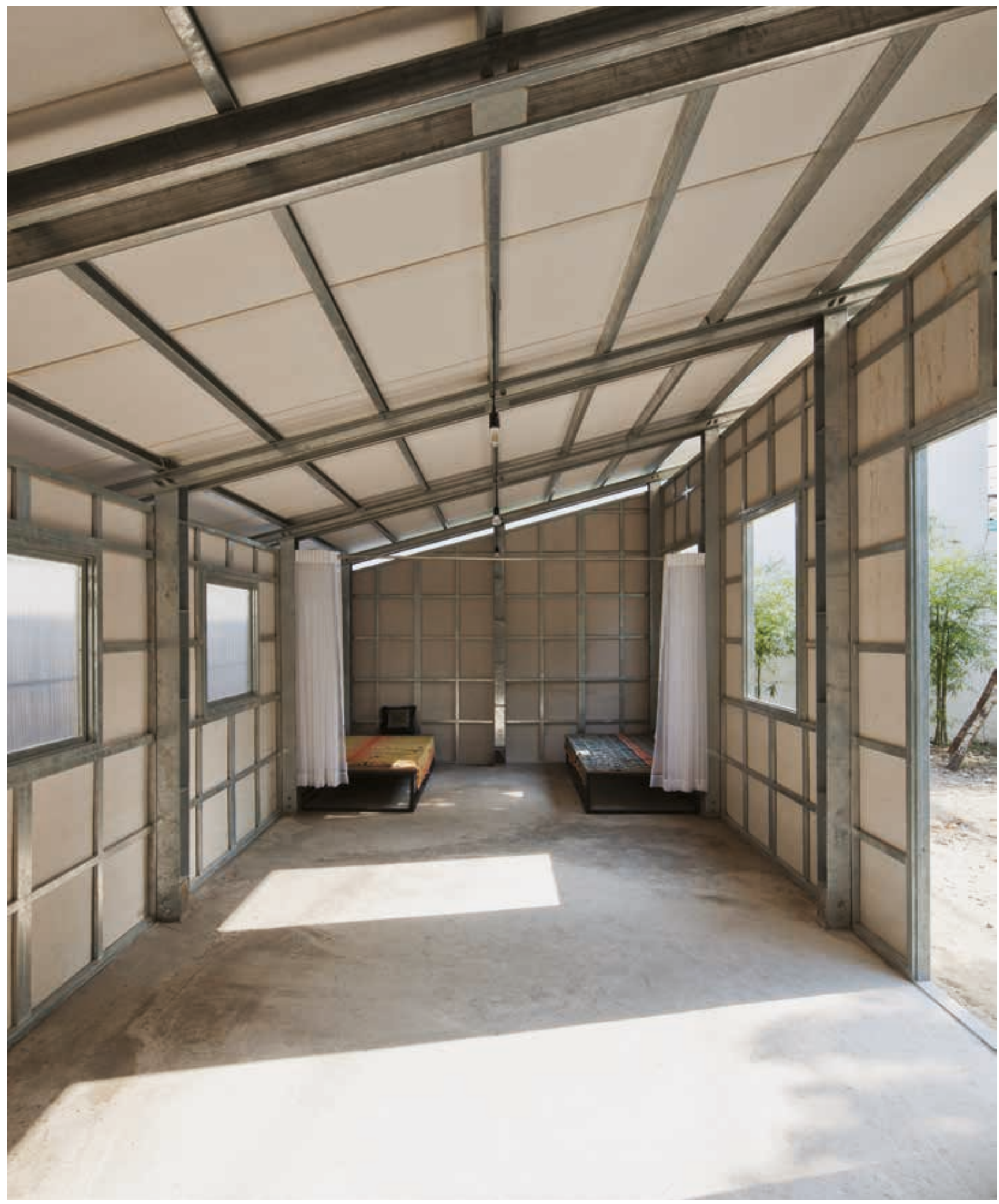

Figure 10. "The aim of this serial project is to provide stable but lightweight, permanent but affordable homes for low-income earners in a harsh tropical climate," says Vo Trong Nghia. (c) Hiroyuki Oki. 


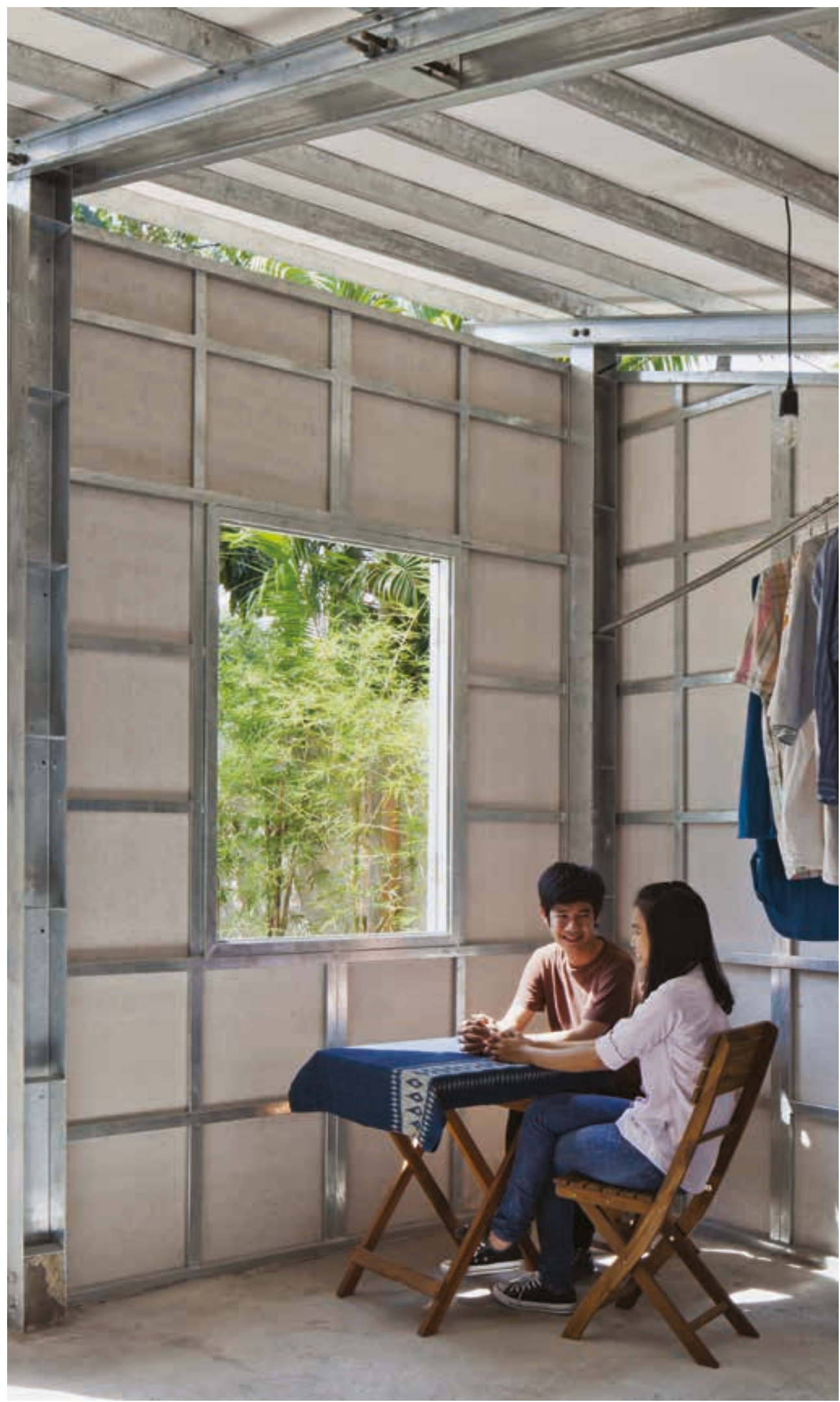

Figure 11. Finishing materials can all be assembled and replaced easily by dwellers and neighbors. For the prototype, lightweight cement board is chosen for cladding. (c) Hiroyuki Oki. 


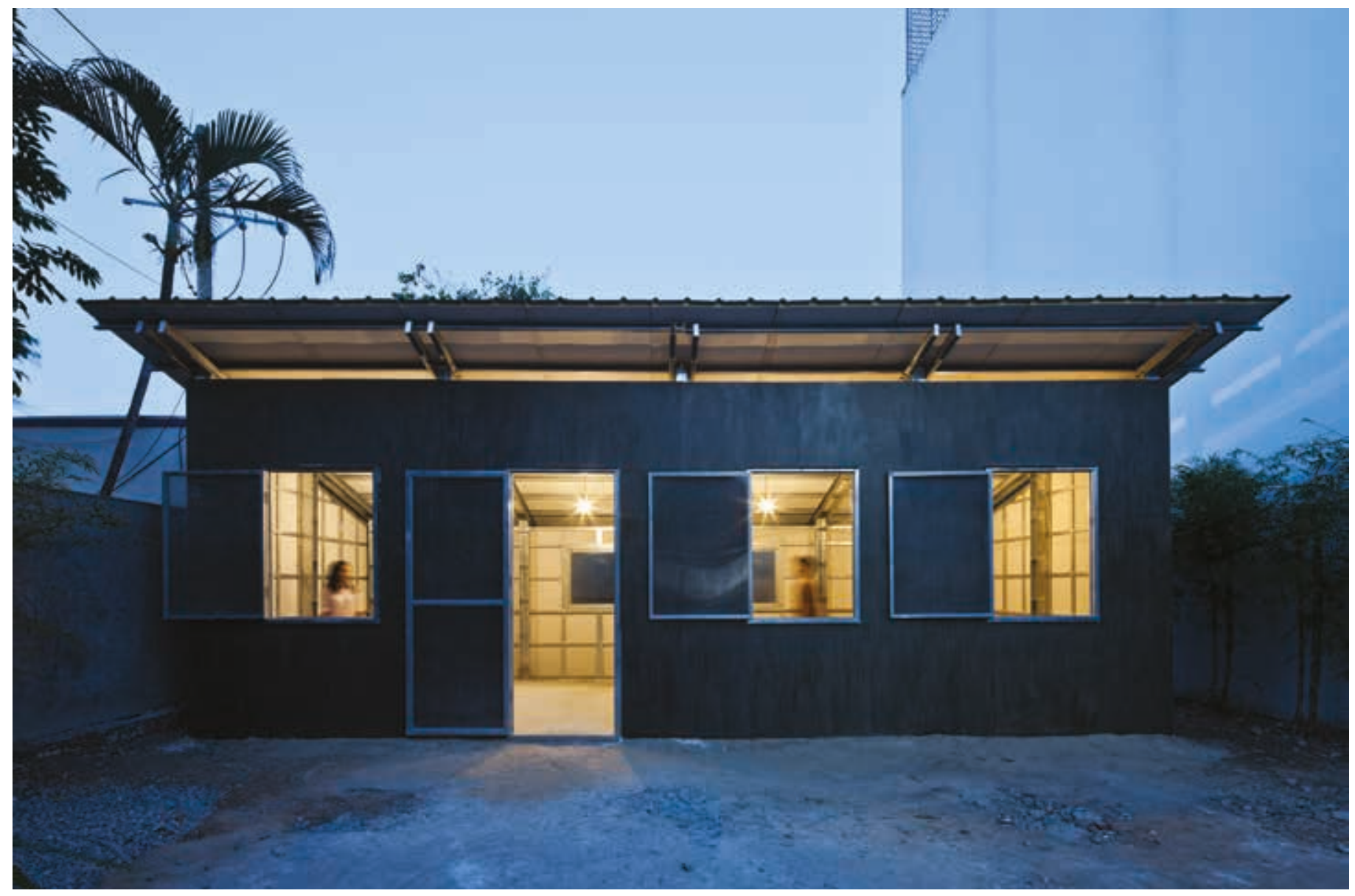

Figure 12. Night view of the model house with interior lighting. () Hiroyuki Oki. 


\section{Project Team}

Architect Firm: Vo Trong Nghia Architects

Principal architects: Vo Trong Nghia, Masaaki Iwamoto, Kosuke Nishijima

Architect: So Adachi

Contractor: Wind and Water House JSC

Status: Built in 11.2014

Program: Prototype house

Location: Ho Chi Minh City, Vietnam

GFA: $31.6 \mathrm{~m}^{2}$

Photographs: Hiroyuki Oki

Vo Trong Nghia, founding partner of Vo Trong Nghia Architects, studied architecture at the University of Tokyo before returning to Vietnam to establish Vo Trong Nghia Architects in 2006. Through a series of the award winning projects, Nghia has developed sustainable architectural design by integrating inexpensive, local materials and traditional skills with contemporary aesthetics and modern methodologies. Nghia has received numerous international prizes and honours including but not limited to; World Architecture Festival Award, ARCASIA award, WAN 21 for 21 Award and, FuturArc Green leadership Award. In 2012, he was selected as the Architect of the year in Vietnam. Besides running his architectural practice, Nghia has continued to be involved in architecture at a grass roots level by teaching at the Nagoya Institute of Technology in 2011. Nghia is registered architect in Vietnam. E-mail: pr@vtnaa.com.

Vo Trong Nghia Architects, Founded in 2006, Vo Trong Nghia Architects is a leading architectural practice in Vietnam with offices in Ho Chi Minh City and Hanoi. More than 60 international architects, engineers and staff work closely on cultural, residential and commercial projects worldwide. By experimenting with light, wind and water, and by using natural and local materials, Vo Trong Nghia Architects employ a contemporary design vocabulary to explore new ways to create green architecture for the $21^{\text {st }}$ century, whilst maintaining the essence of Asian architectural expression. Vo Trong Nghia Architects are in strong collaboration with Wind and Water House JSC, a construction company specializing in green buildings construction, to realize designs of high quality in Vietnam.

(http://votrongnghia.com/company/). 